\title{
Petrographic and Thermal Characterization of Mortar from a Church Ruin in Cagsawa, Albay, Philippines
}

\author{
Nina Muriel A. Laplana ${ }^{1}$, Eric T. Miranda ${ }^{1}$, John Carlo A. Mangay ${ }^{1}$, Angel S. Recto ${ }^{2}$ and Jan-Michael C. Cayme ${ }^{1}$ \\ ${ }^{1}$ School of Chemical, Biological, Materials Engineering and Sciences, Mapua University, Muralla St., Manila, Philippines, 1002 \\ ${ }^{2}$ College of Social Sciences and Philosophy, Bulacan State University, Malolos, Bulacan, Philippines, 3000
}

\begin{abstract}
The Cagsawa Ruins is a crucial structure of the old church standing $38 \mathrm{~km}$ from Mt. Mayon in the province of Bicol. The ruins has been the result of the eruption of Mt. Mayon last February 1, 1814. The remains have become a part of the province's rich history and culture declaring it as one of the national treasures of the Philippines. Preservation is implemented to maintain the part that has remained from centuries ago. But apparently, the material used for preserving this important structure lacks compatibility with the original materials incorporated in the structure. Portland cement has been an alternative for lime mortars through which, in nature, are synthetic and are known to be the source of premature deterioration of soft, historic bricks. This cultural heritage is of importance to the history and must be preserved to its rightful material. By means of petrographic and thermal analysis it was proved that the aggregate from the mortar gathered from Cagsawa came from minerals and marine organisms that the decomposition of the elements confirmed that there are organic compounds present.
\end{abstract}

\section{Introduction}

For almost two centuries the Cagsawa Ruins has stood as a symbol of Bicol region's impressive landscape, rich history and the people's strength and resiliency to face and to rise from the ravages of Mother Nature. The Cagsawa Ruins are what remained of the old Cagsawa community when the near perfect cone-shaped Mayon Volcano erupted early in the morning of February 1, 1814. Accounts of the eruption said columns of rocks and stones shot high into the air killed fleeing residents and set houses on fire as the volcanic debris fell down to earth. Over time, the church building collapsed and today, only the blackened church tower remains standing which is now the centerpiece of the Cagsawa Ruins Park. The Cagsawa bell tower is one of the popular destinations in Albay. Historical structures bring character and certain charm to the neighborhood that people live in. Thus, the preservation and restoration plays a cultural role. Old buildings teach us about the history that happened before we were born and promotes the respect for those who lived in different times and societies [1]. It is important to understand the proper processes of restoration of these old structures using materials that compliments the original structure. Furthermore, this study will benefit other fields of discipline like architecture, history, and archeology.

A mortar is a material resulting from the mixture of sand grains, binder (lime) and water [2]. The properties and characteristic of the mortars mainly depend on the nature of the binder component. That is the reason for which, its evolution with time has been very much related to the development of artificial cementitious materials. Portland cement as a modern day alternative has properties that are incompatible with lime mortar [3]. Aside from its physical difference, Portland cement is harder, less flexible, and impermeable. These qualities lead to premature deterioration of soft, historic bricks. The use of historical methods of low temperature fired, lime mortars with existing mortar of a similar type is a much better treatment for historical building restoration.

This study aims to characterize an old lime mortar that was used in the construction of the historical church ruins in Cagsawa, Albay. This paper will try to investigate by petrographic analysis and thermal analysis, the composition of the lime mortar and the reactions that may occur in the samples undergoing temperature differences [4] that was used in building the ruins of Cagsawa to open an idea to present renovators on how to preserve these important structures.

The utilization of the Petrographic analysis leads us to assess the Physical characteristics of the lime mortar that was gained from the ruins. The chemical analysis of the mortars has also been carried out by using the Thermogravimetric Analyzer on where the samples are being heated up to $1000 \mathrm{C}$ in order to show response of the weight and the samples' decomposition in terms of increasing temperature.

This study mainly encompasses the characterization of mortar used in the ruins of Cagsawa in Barangay Busay, Albay which will strictly focus on the microscopic analysis of the mortar samples. The mortars 
mineralogical constitution is very important to understand the mechanical behavior [5]. There are four samples gathered from different areas in Cagsawa. The first sample is from the west wall of the bell tower, the second sample is from the north wall of the convent, the third and fourth sample is from the east and west wall of Casa Real.

This study is part of a research project approved by the Mapua University, Directed Research for Innovation and Value Enhancement Project (DRIVE) in 2016 Titled: Chemical Analysis of Historic Mortars from Different Spanish Colonial Fortifications in the Philippines.

\section{Materials And Methods}

Four samples were gathered from the ruins of Cagsawa. The samples were detached from broken concretes situated on the ground of the vicinity. The samples were named according to the place where it was obtained (see Table 1 for reference) and was stored in a zip lock bag. Fragments of these samples were subjected to thin section preparation and petrographic analysis. The importance and the limited resources of these ancient materials leads us to handle them carefully for experimentation. Each of the samples were sawn by a 10 inch saw together with an oil lubricant in order to avoid saw rusting. The oil used together with the saw forms a thick sludge that is used to glue the $20 \mu \mathrm{m}$ thickness of the sample in the glass slip. The four samples are examined with petrographic microscope under magnifications 20x and 4x.

Table 1. Name of the sample and the Origin where it was obtained.

\begin{tabular}{|c|c|}
\hline Name & Origin \\
\hline C-01 & West wall \\
\hline C-02 & North wall \\
\hline C-04 & East wall \\
\hline C-05 & West wall \\
\hline
\end{tabular}

Two samples, C-02 and C-04, were subjected to thermal analysis. A STARe Default DB V11.00: METTLER has been used to determine the change of the sample as it is subjected to increasing temperature. A portion of the samples were powdered and weighed to 6.8 micrograms. The sample was then placed on the aluminum pan next to the reference pan, the balance was then tared; the system was purged with nitrogen gas as the sample pan and the reference pan were set to heat at a temperature range of $30^{\circ} \mathrm{C}$ (room temperature) to $1000^{\circ} \mathrm{C}$, with a heat rate of $10^{\circ} \mathrm{C} /$ minute under dynamic air with a purge rate of $20 \mathrm{~mL} /$ minute. The balance then sends the weight signal of the sample pan and the reference pan along with the total time elapsed to the computer. The abscissa (X-axis) is displayed as time or temperature and the ordinate (Y-axis) is displayed as weight $(\mathrm{mg})$ or weight percent $(\%)$.

\section{Results and Discussion}

\subsection{Petrographic Analysis}

Thin sections determines the mineralogy, the quality and the composition of the original lime mortars; microscopic cracks formed in elements and the causes of their occurrence (crystallization under pressure, tensions between mortar and rock), porosity of materials, chemical or biological attack. [8]

Petrographic analysis show homogenous, cohesive binders displaying a strong binder aggregate bond and an absence of over burned and under-burned lime particles. The samples show uniformity as it depicts clastic particles with a conglomerate of rock forming minerals. Each samples are greatly compose of lithic fragments which are a derivation from sedimentary, igneous and metamorphic rocks. They are particles that are eroded down into grains or into sand size. All of the samples are greatly surrounded by micrite and goethite matrix which are constituents of limestone and iron hydroxide minerals. Small percentages of silicate minerals are visible in each sample. Figure 1 shows the 20x magnification view under plane polarized light image of the sample obtained from the west wall of the bell tower. Plagioclase and pyroxene minerals are in minimum percentages as represented by the white particles.

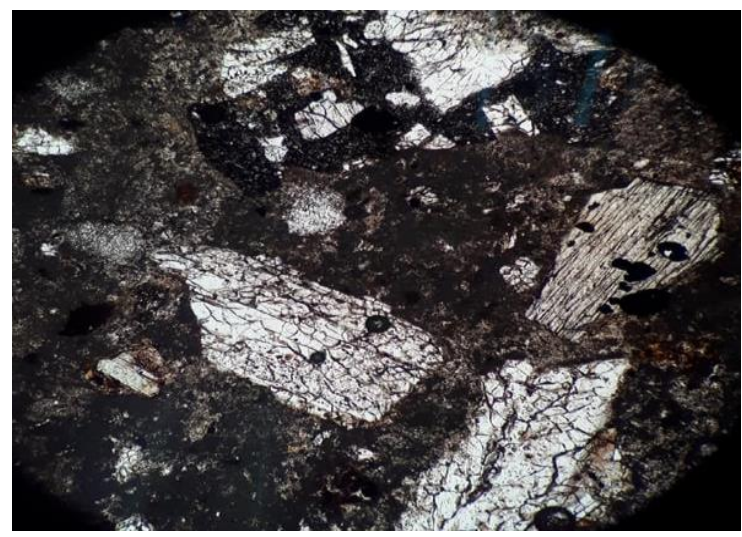

Figure 1. C-01 the sample obtained from the west wall of the bell tower in 20x magnification under PPL (Plane polarized light)

Both of these minerals are silicates, which are made up of silicon oxides and are commonly found on the earth's crust. They are also derived from igneous, metamorphic and sedimentary rocks. The rock particles are all identified as volcanic types through which we can easily tell as it is situated near the Mayon volcano. Fragments of rocks and binder/aggregates that came with the mortar are of easy access. 


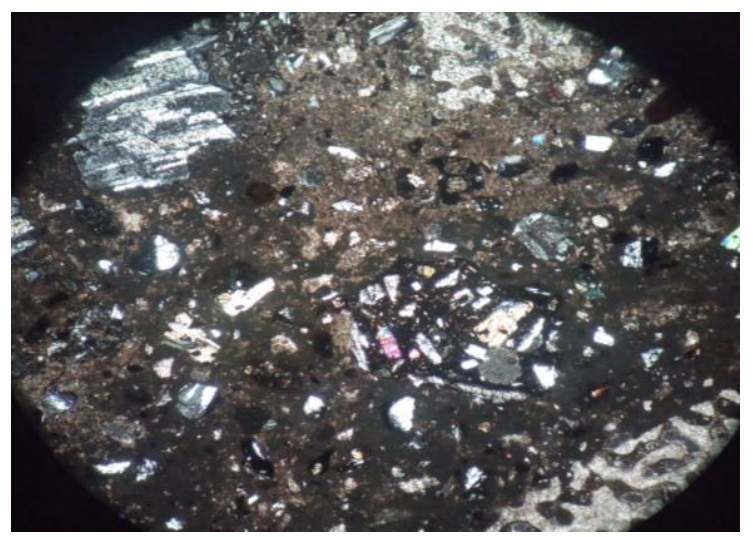

Figure 2. C-01 the sample obtained from the west wall of the bell tower in $4 \mathrm{x}$ magnification under PPL (Plane polarized light)

The 4x magnification view in Figure 2 of sample C01 shows fragments of fossils of living organisms in the marine life. Seashells makes up a bioclast of $40 \%$ in the samples gained that is visibly represented by Figures 1-5. These external skeleton of some marine organisms are known to be rich in calcium oxide content which is an element of decomposition of limestone after being heated at a certain degree.

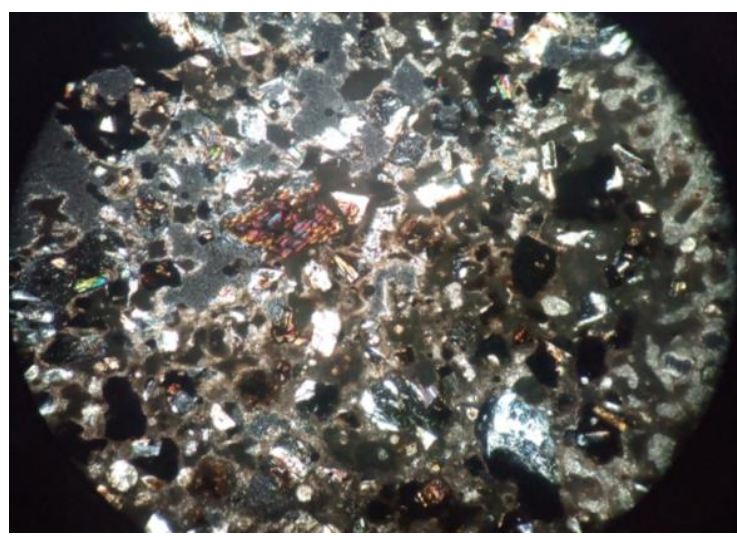

Figure 3. C-02 the sample obtained from the north wall of the bell tower in $4 \mathrm{x}$ magnification under PPL (Plane polarized light)

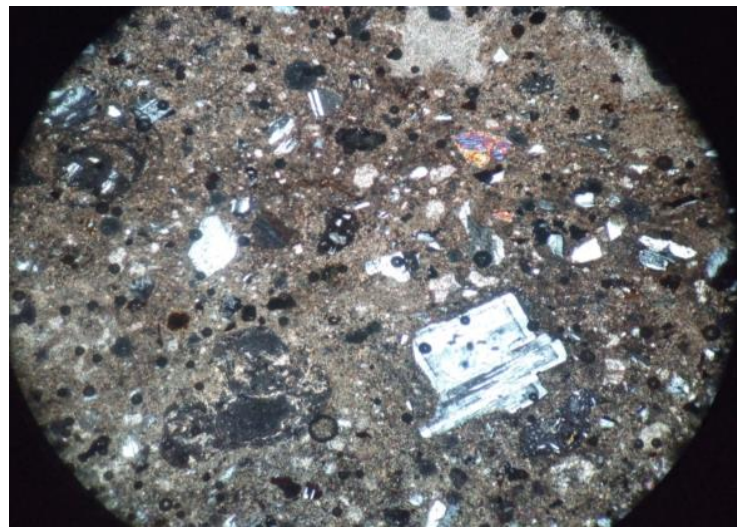

Figure 4. C-04 the sample obtained from the east wall of the Casa Real in 4x magnification under PPL (Plane polarized light)

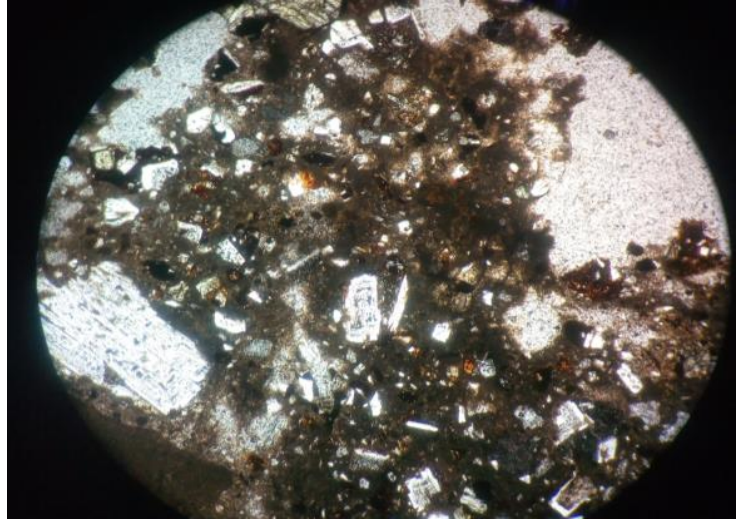

Figure 5. C-05 the sample obtained from the west wall of the Casa Real in 4x magnification under PPL (Plane polarized light)

Crystal twinning also shows on the cross polar image of our C-01 sample on Figure 6. The twinning of crystals occurs when it is subjected to stress or pressure/temperature different from the original process of its formation. Plagioclase is the mineral crystal that forms twinning in the sample. The lattice points of the crystal is formed and shared with the lattice points of another same crystal and there it forms twins of crystals. The said twinning can also tell that the crystals together with other organic fragments and carbon oxide elements are subjected to high temperature and pressure as the mortar is being done.

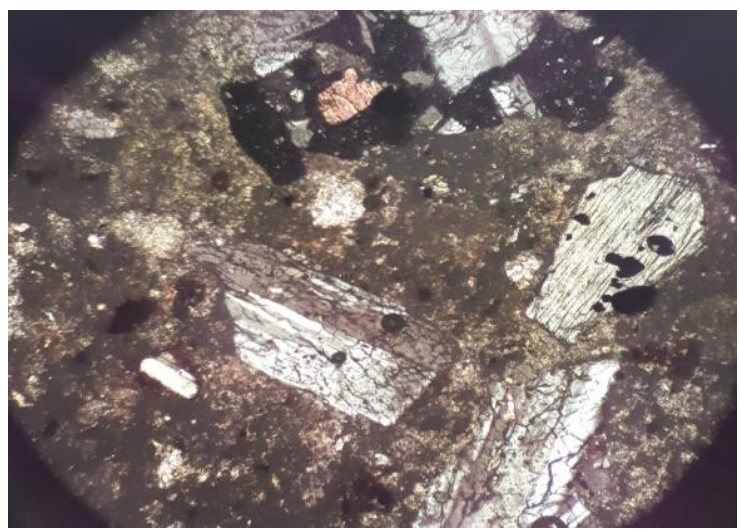

Figure 6. C-01 the sample obtained from the west wall of the bell tower in 20x magnification under XPL (Cross polarized light)

\subsection{Thermal Analysis}

Thermogravimetric analysis shows the nature of the aggregates and other aspects of the mortar when subjected to increasing temperature. This method reveals thermal transformations, which include dehydration, dehydroxylation, oxidation and decomposition [9]. Figure 7 shows that the sample, C-02, decomposes minerals at 680 C. Partial oxidation of the sample is visible at $40 \mathrm{C}$ which resulted to a weight increase of the sample [6]. As temperature increases, the weight of the sample decreases. The decrease in weight that ranges between $100 \mathrm{C}$ to 600 $\mathrm{C}$ is a result of the evaporation of water as well as the combustion of organic matter. The First derivative curve represented by the red line shows a rapid decrease in 
weight of the sample at $670 \mathrm{C}$ visibly indicates a loss of minerals. This rapid decrease can also be the result of the decomposition of the Calcium Carbonate to Calcium Oxide and Carbon Dioxide.

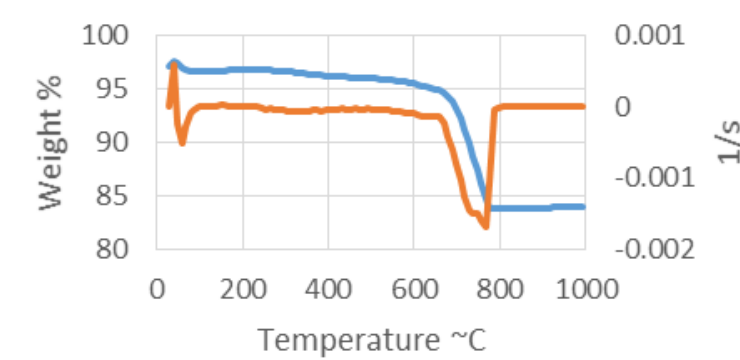

\section{-TGA Curve $\longrightarrow$ First Derivative}

Figure 7. Thermogravimetric Curve of the sample C-02 and its First derivative curve represented by the red line.

Same results also occurred to the sample acquired from the east wall of the bell tower. The First derivative of the curve in Figure 8 also shows an exothermic peak at the initial point. The TGA shows a slight increase of the curve from the initial point up to $600 \mathrm{C}$ which also indicates a slight increase in weight of the sample. A constant decrease in weight of the curve occurred from $600 \mathrm{C}$ up to $690 \mathrm{C}$ indicates a loss of water or moisture incorporated in the sample. The rapid decrease in weight of the sample at $690 \mathrm{C}$ can greatly be attributed by the decomposition of minerals and $\mathrm{CaCO} 3$ from the lime binder.

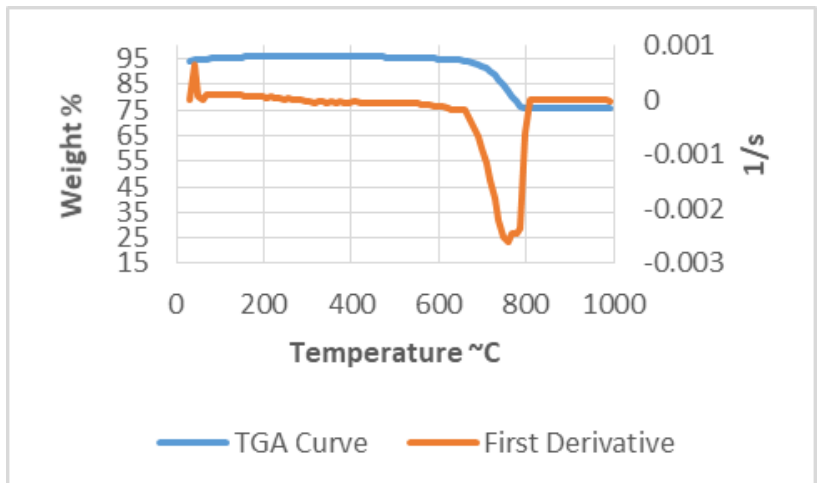

Figure 8. Thermogravimetric curve of the sample C-04 and its first derivative curve represented by the red line.

\section{Conclusion}

The uniformity and the compactness of the binder/aggregate has been evidenced by the petrographic microscope. There are no over-burnt or under-burnt particles. The theoretical reason for this is that the burning of the mortar is strictly observed and being added with pieces of wood from time to time [7].

The twinning of the crystals tell that the process for making the mortar is defined by adding a certain amount of pressure and a certain degree of temperature.

The reactions of the two specimen that have undergone thermogravimetric analysis shows similar reactions under temperature difference. The melting peaks that shows the rapid decrease of weight of the samples are both an indication that reactive minerals have decomposed.

The data gathered from the petrographic analysis used in this study has determined the main composition of the mortar. It is evidenced that the mortar is composed of external skeleton of some marine organisms that makes up the aggregate of the material from which can be concluded that the materials used came from local sources. It also emphasizes the lime that makes up the binder of the mortar.

The results gained from the two techniques makes a crucial amount of information and has met similar results as displayed by the decomposition of the elements in the mortar seen in the TGA graphs is a confirmation that organic compounds are present.

\section{References}

1. R.Archivotli, Imp. of Save. H. MONT (2014)

2. E.S Goins, Standard Practice for Determining the Components of Historic Cementitious Materials, 6 (2002)

3. L. Strenchock, Res. On Rest. Of HTE Struc. (2009)

4. J.I. Alvarez, I. Navarro, P.J. Garcia Casado. Therm., Min. and Chem. Stud. Of the Mortars used in the Cathedral of Pamplona(Spain)

5. P.C. Raposo, J.A.F.O. Correia, D. Sousa, M.E. Salavessa, C. Reis, C. Oliveira, Abilio De Jesus PETRA. Char. Part. Wall Mortars of a $19^{\text {th }}$ Cent. Bldg (2017)

6. Jan-Michael C. Cayme, Aniano N. Asor, Jr., Maveen Kim Alexis T. Alano and Eric T. Miranda. "Chemical Characterization of Historical Brickwork of the Church Convento in Pagsanjan, Laguna" (2016)

7. Regalado Trota Jose, Zero In (2003)

8. N. Cobirzan, A.-A. Balog, Characterzation of Mortars Compatibility using Microcopical and XRD Analysis (2013)

9. A. Moropoulou, A. Bakolas, K.Bisbikou. Characterization of Ancient Byzantine and later Historic Mortars by Thermal and X-ray Diffraction Techniques (1995). 